\title{
Equilibrative nucleoside transporter (ENT)-1-dependent elevation of extracellular adenosine protects the liver during ischemia and reperfusion
}

\author{
Michael A. Zimmerman ${ }^{1,{ }^{*}}$, Eunyoung Tak ${ }^{2,{ }^{*}}$, Stefan F. Ehrentraut ${ }^{3}$, Maria Kaplan ${ }^{1}$, Antasia \\ Giebler $^{2}$, Tingting Weng ${ }^{5}$, Doo-Sup Choi ${ }^{4}$, Michael R. Blackburn ${ }^{5}$, Igal Kam ${ }^{1}$, Holger K. \\ Eltzschig ${ }^{2}$, and Almut Grenz ${ }^{2}$ \\ ${ }^{1}$ Division of Transplant Surgery, Department of Surgery, University of Colorado \\ ${ }^{2}$ Mucosal Inflammation Program, Department of Anesthesiology, University of Colorado \\ ${ }^{3}$ Mucosal Inflammation Program, University of Colorado \\ ${ }^{4}$ Department of Molecular Pharmacology and Experimental Therapeutics, Mayo Clinic College of \\ Medicine, Rochester, Minnesota \\ ${ }^{5}$ Department of Biochemistry and Molecular Biology, The University of Texas Health Science \\ Center at Texas, Houston, Texas, USA
}

\begin{abstract}
Ischemia and reperfusion-elicited tissue injury contributes to morbidity and mortality of hepatic surgery or during liver transplantation. Previous studies had implicated extracellular adenosine signaling in liver protection. Based on the notion that extracellular adenosine signaling is terminated by uptake from the extracellular towards the intracellular compartment via equilibrative nucleoside transporters (ENTs), we hypothesized a functional role of ENTs in liver protection from ischemia. During orthotopic liver transplantation in humans, we observed higher expressional levels of ENT1 than ENT2, in conjunction with repression of ENT1 and ENT2 transcript and protein levels following warm ischemia and reperfusion. Treatment with the pharmacologic ENT inhibitor dipyridamole revealed elevations of hepatic adenosine levels and robust liver protection in a murine model of liver ischemia and reperfusion. Subsequent studies in gene-targeted mice for Entl or Ent2 demonstrated selective protection from liver injury in Ent1 ${ }^{-1-}$ mice. Treatment with selective adenosine receptor antagonists indicated a contribution of Adora2b receptor signaling in ENT-dependent liver protection. Taken together, these findings implicate ENT1 in liver-protection from ischemia and reperfusion injury and suggest ENT inhibitors in the prevention or treatment of ischemic liver injury.
\end{abstract}

\section{Keywords}

adenosine; equilibrative nucleoside tranporter; liver transplantation; liver surgery; inflammation; hypoxia; ischemia and reperfusion

\footnotetext{
Address correspondence to: Holger K. Eltzschig, MD, PhD, and Almut Grenz, MD, PhD, Mucosal Inflammation Program, Department of Anesthesiology, University of Colorado Denver, 12700 E $19^{\text {th }}$ Avenue, Mailstop B112, Research Complex 2, Room 7124, Aurora, CO 80045, Office: 303-724 -2931 or - 2947, Fax: 303-724-2936, holger.eltzschig@ ucdenver.edu, almut.grenz@ucdenver.edu.

* contribute equally to this work

Conflict of interest: The authors have declared that no conflict of interest exists.
}

Authors contributions: MZ, AG, ET, SE, MK, AG, MRB researched data. DSC, IK provided new research tools. HKE, AG, MZ wrote the manuscript. 


\section{Introduction}

Ischemia and reperfusion is a pathologic condition characterized by an initial restriction of blood supply to an organ, followed by the subsequent restoration of perfusion and concomitant re-oxygenation $(1,2)$. In its classic manifestation, occlusion of the arterial blood supply is caused by an embolus and results in a severe imbalance of metabolic supply and demand causing tissue hypoxia. In the second stage of the disease, blood flow is rapidly restored. Somewhat surprisingly, the restoration of blood flow along with re-oxygenation is frequently associated with an exacerbation of tissue injury and a profound inflammatory response (so called "reperfusion injury") (3). While ischemia and reperfusion contribute significantly to a wide range of pathologies, its functional contribution during liver surgery is particularly severe. For example, ischemia and reperfusion is a frequent cause of acute liver failure during orthotopic liver transplantation. Similarly, ischemia and reperfusion injury can contribute to immunologic consequences during human liver transplantation, as it is implicated in early rejection of the transplanted liver graft or the recurrence of hepatitis $\mathrm{C}$ in patients undergoing liver transplantation for the treatment of chronic hepatitis. Moreover, treatment modalities that would prevent hepatic ischemia and reperfusion injury are very limited and studies that aim to identify novel therapeutic approaches for hepatic ischemia and reperfusion are an area of intense investigation $(4,5)$.

Previous studies had shown that ischemia and reperfusion is associated with increased adenosine production from its precursor molecules - particularly the nucleotides ATP, ADP and AMP $(1,6)$. Furthermore it has been shown that activation of cAMP-dependent protein kinase A regulates local inflammation and prevents hepatocyte death (7). Extracellular adenosine can signal through four distinct adenosine receptors (ARs), the Adora1, Adora2a, Adora2b or the Adora3.(1) Studies of hepatic ischemia and reperfusion had shown a functional role for extracellular adenosine production $(8,9)$, and signaling events through ARs - such as the Adora2a (10) and Adora2b (11) - in liver protection from ischemia. Based on the notion that extracellular adenosine signaling is terminated via uptake of adenosine from the extracellular towards the intracellular compartment via equilibrative nucleoside transporters (ENTs) (12-15), we pursued the hypothesis that inhibition of extracellular adenosine uptake could represent a means of enhancing hepatic adenosine signaling and concomitant liver protection from ischemia. Indeed, by attenuating adenosine uptake, and concomitant increases of spontaneously formed extracellular adenosine levels, endogenously generated levels of extracellular adenosine could become sufficient to trigger immunosuppressive adenosine receptor signaling events within the inflamed liver tissue microenvironments in vivo $(16,17)$. In other words, the molecular concept is that pathophysiologically-induced elevations of extracellular adenosine can provide better liver protection, if they are elevated over a longer time period, which can be achieved by adenosine uptake inhibitors, or by genetically targeting individual adenosine transporters. Therefore, we combined studies of ENT transcript and protein levels in biopsy samples obtained from patients undergoing liver transplantation with pharmacologic and genetic studies in a previously described model of murine partial hepatic ischemia and reperfusion $(8,9,18)$. These studies demonstrated a selective role for ENT1 in elevating hepatic adenosine levels and conveying liver protection from ischemia and reperfusion injury.

\section{Methods}

\section{Human liver tissue}

Liver samples were obtained from patients undergoing orthotopic liver transplantation (Supplementary Table 1). Liver biopsies (I) were taken at the conclusion of cold ischemia time (CIT) during back table preparation of the cadaveric liver allograft (Figure 1A). A 
second biopsy (R) was taken immediately prior to closure of the abdomen following drain placement (Figure 1A). Importantly, total reperfusion time is defined as the time from portal vein perfusion to abdominal closure at the conclusion of the procedure.

Mice

All animal protocols were in accordance with the University of Colorado, Denver guidelines. Ent1 on the C57BL/6J strain were generated, validated, and characterized as previously described (19). Ent2-deficient mice were obtained from Taconic. Conditional

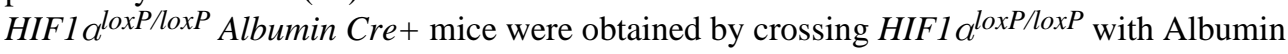
Cre+ mice (Jackson Laboratory). In all control experiments, age-, gender-, and weightmatched littermate controls were used.

\section{Murine model of partial liver ischemia}

In an effort to avoid mesenteric congestion, a murine model of partial liver ischemia was employed using a hanging-weight system as previously described (18).

\section{Transcriptional analysis}

Ent1 and Ent2 transcript levels were measured by (RT)-PCR (iCycler, Bio-Rad Laboratories Inc.) as previously described (20).

\section{Immunoblotting}

In both human and mouse tissues Ent 1 and Ent 2 protein content was determined at different time points as previously described (20).

\section{Isolation of hepatocytes}

Liver preparation was performed as decribed in detail by Wei et al (21).

\section{ELISA (IFNY, IL6, MPO)}

IFN $\gamma$, IL-6 (R\&D Systems) and neutrophil sequestration was quantified according to the manufacturer instructions.

\section{Adenosine measurement}

Livers were removed and immediately snap frozen after $45 \mathrm{~min}$ of liver ischemia without reperfusion. Adenosine was measured as previously described (22).

\section{Liver histology}

Liver tissue was harvested following 2 or 24 hours of reperfusion. Sections $(3 \mu \mathrm{m})$ were stained with hematoxylin and eosin (HE). Examination and scoring (Suzuki Scoring 0-4) based on the presence and/or severity of sinusoidal congestion, cytoplasmic vacuolization, and necrosis of parenchymal cells was performed for 6 representative sections of each liver sample ( $\mathrm{n}=4-6$ for each condition) in a blinded fashion (9). Tissue injury was scored

\section{Statistical Analysis}

Liver injury score data are given as median and range. All other data are presented as mean \pm SD from three to eight animals per condition. We performed statistical analysis using the Student's t test. A value of $p<0.05$ was considered statistically significant. For Western blot analysis 2 to 3 repeats were performed. For all statistical analysis GraphPad Prism 5.0 software for Windows XP was used. 


\section{Study Approval}

Collection and use of patient samples were approved by the COMIRB at UCDenver. All animal protocols were in accordance with the United States Guidelines IACUC for use of living animals and were approved by the Institutional Animal Care and Use Committee of the University of Colorado guidelines for animal care.

\section{Results}

\section{Human ENT transcript and protein levels are repressed following orthotopic liver transplantation}

Previous studies had indicated that termination of extracellular adenosine signaling is terminated via uptake of adenosine from the extracellular towards the intracellular compartment via ENTs.(12-15) Such studies also revealed that the transcriptional regulation of ENTs represents an important regulatory mechanism to alter adenosine signaling events. For example, transcriptional repression of ENTs during hypoxia results in enhanced extracellular adenosine accumulation and represents an endogenous anti-inflammatory pathway to dampen hypoxia-induced inflammation.(12,15) Along the lines of these studies, we pursued the hypothesis that ENTs could be important regulators of hepatic adenosine signaling during liver ischemia, thereby contributing to adenosine-dependent liver protection from ischemia. Therefore, we examined the expression of ENTs in human liver biopsy samples. We obtained biopsy samples during orthotopic liver transplantation, with the first biopsy taken following organ procurement and cold ischemia (baseline) and the second biopsy sample after warm ischemia and reperfusion (Fig. 1A). Donor and patient characteristics, as well as ischemia and reperfusion times are displayed in Table 1. Consistent with previous studies in murine models of renal ischemia, we observed that human ENT1 and ENT2 transcript levels are repressed following warm ischemia and reperfusion (Fig. 1B). Hepatic protein levels of ENT2 are very low during ischemia and after reperfusion whereas ENT1 protein levels show a stronger expression during ischemia and show a severe decrease following liver ischemia and reperfusion (Fig. 1C). We correlated the amount of ENT1/ENT2 protein expression to outcome parameters (e.g. AST, ALT), but based on the low number of biopsy samples, we cannot state a correlation between the recovery phase of the recipient related to the amount of ENT protein expression in the liver biopsies. However, the expression levels of ENT1 and ENT2 were consistent with studies of murine Ent 1 and Ent2 expression in a model of partial hepatic ischemia and reperfusion (Fig. 2A). Indeed, murine Ent1 and Ent2 transcript and protein levels were repressed following $45 \mathrm{~min}$ of liver ischemia and 2 hours reperfusion (Fig. 2B,C). Together these studies demonstrate that hepatic ENT1 and ENT2 transcript levels are repressed during conditions of limited oxygen availability, indicating the likelihood of a transcriptional regulated endogenous protective pathway directed towards enhancing extracellular adenosine levels and signaling during liver ischemia and reperfusion injury.

\section{Pharmacologic inhibition of ENTs with dipyridamole is associated with elevated hepatic adenosine levels and conveys liver protection}

After having shown that ENT1 and ENT2 are transcriptionally regulated during liver ischemia and reperfusion as occurs during human liver transplantation, we next pursued studies to address their functional contributions to the regulation of extracellular adenosine levels and outcomes of hepatic ischemia and reperfusion injury. For this purpose, we exposed mice to $45 \mathrm{~min}$ of partial hepatic ischemia and $2 \mathrm{~h}$ of reperfusion. In order to address the functional role of ENTs, we pretreated the experimental animals with intravenous dipyridamole $(0.5 \mathrm{mg} / 25 \mathrm{~g}$ mouse IV) $15 \mathrm{~min}$ prior to the onset of liver ischemia (Fig. 3A). Indeed, studies utilizing HPLC to measure hepatic adenosine levels in ischemic livers that were shock frozen immediately following $45 \mathrm{~min}$ of hepatic triad occlusion revealed 
elevations of adenosine levels following ischemia. Importantly, these elevations of adenosine were further enhanced in mice pre-treated with dipyridamole (Fig. 3B). Subsequent functional studies of the clinical outcome of hepatic ischemia and reperfusion injury revealed that mice pre-treated with dipyridamole experienced attenuated plasma levels of AST and ALT and a less severe degree of hepatic tissue injury 2 hours (Fig. 3C,D) and 24 hours (Fig. 3E,F) following hepatic ischemia, indicating a protective role of dipyridamole in liver ischemia and reperfusion. Together, these studies demonstrate that ENT inhibition with dipyridamole is associated with liver protection from ischemia and reperfusion injury via enhancing hepatic adenosine levels and signaling events.

\section{Selective genetic deletion of Ent1 mediates hepatic adenosine elevations and liver protection from ischemia and reperfusion injury}

After having shown that non-specific inhibition of ENTs with dipyridamole is associated with elevated hepatic adenosine levels and concomitant liver protection from ischemia, we next pursued studies to address the functional contributions of Ent1 versus Ent2. For this purpose we exposed previously described mice for Ent1 or Ent2 to liver ischemia, $(13,19)$ to liver ischemia and measured hepatic adenosine levels and assessed liver injury. Indeed, we observed that Ent1 ${ }^{-/-}$mice experienced significantly higher post-ischemic adenosine levels as compared to littermate controls matched age, gender and sex when exposed to 45 min of partial liver ischemia (Fig. 4A). Moreover, Ent1 ${ }^{-/-}$mice experienced less pronounced elevations of plasma ALT and AST (Fig. 4B) and histologic liver injury (Fig. 4C) following 45 min of liver ischemia and $2 \mathrm{~h}$ of reperfusion. In addition, we observed that liver inflammation induced by ischemia and reperfusion was significantly attenuated in Ent1 ${ }^{-/-}$ mice (Fig. 4D). Moreover, second organ injury of the lungs induced by liver ischemia and reperfusion was significantly attenuated in Ent1 ${ }^{-/-}$mice (Fig. 4E). In addition, we performed experiments with prolonged reperfusion times. In these experiments, we followed 45 minutes of liver ischemia with 24 h of reperfusion. Indeed, Ent1 ${ }^{-/-}$mice exhibited significantly lower levels of tissue injury as examined by elevations of the transaminases AST and ALT and liver histology (Fig. 4F,G) after $24 \mathrm{~h}$ of reperfusion time. In contrast $E n t 2^{-/-}$mice exposed to liver ischemia failed to demonstrate more pronounced elevations of ischemia-induced adenosine levels (Fig. 5A), and showed similar levels of liver injury and liver inflammation as corresponding littermate control mice (Fig. 5B-D). Moreover, secondary organ injury of the lungs was similar in Ent2 ${ }^{-/}$mice or controls following hepatic ischemia and reperfusion (Fig. 5E). In addition, liver injury was similar also after prolonged reperfusion time ( 24 hours, Fig. 5F,G). Taken together, these findings demonstrate for the first time a selective role for Ent1 in liver protection from ischemia and reperfusion injury.

\section{ENT1-dependent liver protection from ischemia and reperfusion injury involves signaling events through the Adora2b}

After having shown that pharmacologic inhibition or genetic deletion of Ents is associated with elevated hepatic adenosine levels, and concurrent protection from ischemic hepatic injury, we next pursued the hypothesis that Ent-dependent liver protection involves adenosine signaling. To address this hypothesis, we treated Entl gene-targeted mice with an Adora $2 \mathrm{a}$ or Adora $2 \mathrm{~b}$ antagonist and thus examined if blockade of one of these adenosine receptors abolishes the protective effect of Ent1-dependent adenosine generation. The dosing for the antagonists have been chosen based on previous publication showing an effect in organ injury (23-25). While mice with pretreatment with the Adora2a specific antagonist ZM241385 (2mg/kg IV) showed a similar degree of liver protection as Ent1 ${ }^{-/}$- without treatment (Fig. 6A,B), whereas Ent1 ${ }^{-/-}$mice with pretreatment with the Adora2b specific antagonist PSB1115 (0.5mg/25g mouse IV) were not protected compared to Ent1 ${ }^{-/-}$without treatment (Fig. 6C-F). Together, these studies indicate that kidney protection mediated by 
the ENT inhibitor dipyridamole involves signaling events through Adora2b during ischemic hepatic injury.

\section{HIF1a-dependent regulation of ENT's and Adora receptors following liver ischemia and reperfusion injury}

After having shown the impact of adenosine re-uptake via ENT1 and adenosine signaling via the Adora2b receptor during liver ischemia and reperfusion injury we next wanted to investigate the transcriptional regulated pathway of these proteins. Since previous studies identified HIF1a regulating ENT1 and Adora2b receptor expression we utilized a novel mouse line with deletion of HIF1a in hepatocytes (HIFla ${ }^{\text {loxPlloxP }}$ Albumin Cre+, Figure 7A) and studied ENT1/ENT2 and adenosine receptor expression with and without liver ischemia. Interestingly, ENT1 and ENT2 transcript levels were at baseline higher in the conditional HIF knockout mice compared to the appropriate controls (Fig. 7B). Furthermore, neither ENT1 nor ENT2 were repressed following liver ischemia in contrast to the control mice. Moreover, the increase in Adora2b receptor transcript following liver ischemia in control mice was absent in HIFla ${ }^{\text {loxP/loxP }}$ Albumin Cre+ mice (Fig. 7C). These findings are consistent with previous studies which identified a transcriptionally regulated pathway for ENT1, ENT2 and Adora2b involving $\operatorname{HIF}(15,26)$. Together, these studies indicate that ENT1 and Adora2b are transcriptionally regulated via HIF1a during liver ischemia and reperfusion injury.

\section{Discussion}

Hepatic ischemia and reperfusion injury significantly contributes to the mortality and morbidity of major hepatic surgery and liver transplantation. Moreover, therapeutic approaches to dampen ischemia and reperfusion mediated tissue injury are extremely limited, and studies trying to identify novel therapeutic targets are an area of intense research. Based on previous studies showing that levels of the anti-inflammatory signaling molecule adenosine are tightly regulated by adenosine transporters (particularly ENTs), we pursued the hypothesis that ENTs can be targeted to increase hepatic adenosine signaling and thereby mediate liver protection from ischemia and reperfusion. Indeed, these studies demonstrated that particularly ENT1 is expressed in the human liver, and ENT1/2 transcript levels are repressed following liver transplantation in humans. Functional studies with the ENT inhibitor dipyridamole demonstrated liver protection in conjunction with elevations of extracellular adenosine levels. Moreover, we observed a selective phenotype in Ent1 $1^{-/-}$ mice characterized by elevation of hepatic adenosine levels and profound hepato-protection from ischemia and reperfusion injury. Subsequent studies with pharmacologic blockers of adenosine signaling revealed that the observed protection in $E n t 1^{-/-}$mice predominantly involves the Adora2b. Furthermore we could show that Ent1/Ent2 and Adora2b are transcriptionally regulated via HIF1a by utilizing conditional mice. Taken together, these studies demonstrate a functional role for ENT1 in liver protection from ischemia and reperfusion injury and implicate ENT inhibitors in the treatment of ischemic liver injury.

The present findings demonstrate attenuated ENT1 and ENT2 transcript levels following ischemia and reperfusion during human liver transplantation, or during murine liver ischemia and reperfusion. These studies are consistent with previous findings showing repression of ENTs during conditions of limited oxygen availability. In fact, ambient hypoxia exposure of vascular endothelia (12) cardiac myocytes(27), or intestinal epithelial cells $(12,15)$ is associated with repression of ENT1 and ENT2 transcript and protein levels. Studies on the regulatory mechanism coordinating these responses revealed that both, the ENT1 and the ENT2 promoter contain binding sites for the transcription factor hypoxiainducible factor (HIF).(12, 15) Subsequent studies with transcription factor binding assays, 
promoter constructs, or HIF loss- or gain-of-function revealed that HIF directly binds to the promoter regions of ENT1 or ENT2, and mediates ENT repression during hypoxia. We could confirm these findings by utilizing a transgenic mouse line with a floxed HIF1a gene to generate a mouse line with deletion of HIF1a in hepatocytes. The repression of hepatic ENT1/ENT2 following liver ischemia was absent in these mice. Furthermore the induction of Adora2b receptor following liver ischemia was abolished indicating that these proteins are transcriptionally regulated via HIF1a. Indeed, HIF is responsible for the transcriptional regulation of a coordinated response that results in increased extracellular adenosine signaling effects during hypoxia. In addition to repression of ENT1/ENT2, this response includes the transcriptional induction of CD73 - the key enzyme for extracellular adenosine generation, $(24,28-32)$ and the Adora2b receptor. $(24,33-37)$. In addition to transcriptional repression by direct binding of transcription factors to a gene promoter, transcriptional repression is frequently mediated by transcriptional induction of miRNAs. Previous studies had shown that ENT1 or ENT2 are regulated during conditions of ambient hypoxia by direct binding of HIF1a to the promoter of ENT1, or ENT2 respectively $(15,26)$. However, it is also conceivable that ENT repression could be mediated by HIF dependent induction of miRNAs that would target ENT mRNA. Indeed, several previous studies have implicated miRNA induction and subsequent transcriptional repression of target genes during conditions of ischemia or hypoxia (2). Several previous studies have demonstrated a protective role of adenosine signaling during inflammatory conditions. Indeed, the first report that patho-physiologically-induced extracellular adenosine signaling via the Adora2a receptor is critically important and non-redundantly responsible for the immunosuppression during inflammation in vivo in the absence of any drug comes through a land-mark paper from the research group of Dr. Sitkovsky $(16,38,39)$. Subsequent in vivo studies from the laboratory of Dr. Ravid suggested that also signaling events through the Adora2b can dampen vascular inflammatory responses in response to endogenous elevations of extracellular adenosine levels in vivo (40). Moreover, pharmacologic studies from Dr. Bruce Cronstein's laboratory established a functional role of adenosine receptor signaling in attenuating inflammatory cell activation.(41). Moreover, studies from the laboratory of Dr. Joel Linden demonstrated that activation of Adora2a receptors on inflammatory cells particularly on natural killer T-cells - are involved in liver protection from ischemia (10). In contrast to these studies, the present findings implicate the Adora2b in ENT-mediated liver protection from ischemia. Consistent with these findings, several previous studies had implicated the Adora2b in tissue protection from ischemia.(24, 35-37, 42-45) In addition, it is conceivable that the timing of the injury model may contribute to such differences; while early on (e.g. $2 \mathrm{~h}$ after reperfusion) the dominant protective pathway could involve the Adora2b, later inflammatory changes (particularly involving T-cells) could be attenuated by the Adora2a.

Several studies have demonstrated that while adenosine signaling through the Adora2b may be beneficial in an acute setting, this adenosine protection can become detrimental when it is prolonged (46-49). Indeed, studies in a chronic liver disease model have shown detrimental effects of Adora2b signaling, utilizing fatty liver disease - commonly associated with alcohol ingestion and abuse - as a model $(50,51)$. During ethanol metabolism, adenosine is generated by the enzyme ecto-5'-nucleotidase, and adenosine production and adenosine receptor activation are known to play critical roles in the development of hepatic fibrosis. Dr. Cronstein's laboratory team therefore investigated whether adenosine and its receptors play a role in the development of alcohol-induced fatty liver. WT mice fed ethanol on the Lieber-DeCarli diet developed hepatic steatosis, including increased hepatic triglyceride content, while mice lacking the ecto-5'-nucleotidase CD73 or Adora1 or Adora2b receptors were protected from developing fatty liver disease. These studies indicate that adenosine generated by ethanol metabolism plays an important role in ethanol-induced hepatic 
steatosis via both Adora1 and Adora2b and suggest that targeting adenosine receptors may be effective in the prevention of alcohol-induced fatty liver (50).

Hepatic ischemia and reperfusion injury significantly contributes to morbidity and mortality of surgical patients undergoing liver transplantation. Indeed, the present studies reveal several lines of potential treatment modalities that could be used to prevent or treat hepatic ischemia and reperfusion injury. As first line of treatment, the present studies suggest that HIF activators could be used to treat liver ischemia and reperfusion injury. Such compounds would result in repression of ENTs, thereby promoting adenosine-dependent liver protection. At the same time, these compounds would also increase extracellular adenosine production and signaling, by transcriptionally inducing enzymes that produce adenosine during ischemic conditions (1-4). Interestingly, a recent clinical trial shows that HIF activators can be safely used in patients for the treatment of renal anemia (5). A second line of treatment could be to use the ENT dipyridamole - either as a means of prophylactically treating patients during liver surgery, or as an addition to liver conservation solutions during liver transplantations. Again, dipyridamole has a great safety record in patients, for example for the prevention of recurrent stroke or to maintain patency of dialysis grafts $(6,7)$. As a third approach, adenosine receptor agonists - particularly for the Adora $2 \mathrm{~b}$ could be used. In fact, we recently described and characterized a highly selective adenosine receptor agonist BAY 60-6583. Finally, additional therapeutic approaches that would enhance hepatic conversion of ATP to adenosine, for example by treating with soluble apyrase (conversion of ATP/ADP to AMP) (8-11), or nucleotidase (conversion of AMP to adenosine) $(12,13)$ could be considered.

Taken together, the present studies provide evidence that ENT1 (and to a lesser degree ENT2) is expressed in the human livers. Subsequent studies in mouse models of liver ischemia and reperfusion point towards a therapeutic role of ENT1 inhibition in this model, as it is associated with elevated hepatic adenosine levels and protective signaling effects through the Adora2b receptor. Future challenges will include clinical studies with ENT inhibitors or Adora $2 \mathrm{~b}$ agonists to examine if the present findings can be translated from bench to bedside.

\section{Supplementary Material}

Refer to Web version on PubMed Central for supplementary material.

\section{Acknowledgments}

The present research work was supported by 1 KO8HL103900-01 to MZ, an American Heart Association Grant to AG and National Heart Institute Grants R01 DK097075, R01-HL0921, R01-DK083385, R01- HL098294, POIHL114457-01 and a grant by the Crohn's and Colitis Foundation of America (CCFA) to HKE.

\section{References}

1. Eltzschig HK, Eckle T. Ischemia and reperfusion--from mechanism to translation. Nat Med. 2011; 17:1391-1401. [PubMed: 22064429]

2. Eltzschig HK, Carmeliet P. Hypoxia and inflammation. N Engl J Med. 2011; 364:656-665. [PubMed: 21323543]

3. Yellon DM, Hausenloy DJ. Myocardial reperfusion injury. N Engl J Med. 2007; 357:1121-1135. [PubMed: 17855673]

4. Zhang Y, Ji H, Shen X, Cai J, Gao F, Koenig KM, Batikian CM, et al. Targeting TIM-1 on CD4 T Cells Depresses Macrophage Activation and Overcomes Ischemia-Reperfusion Injury in Mouse Orthotopic Liver Transplantation. Am J Transplant. 2013; 13:56-66. [PubMed: 23137033] 
5. Ke B, Shen XD, Kamo N, Ji H, Yue S, Gao F, Busuttil RW, et al. beta-Catenin regulates innate and adaptive immunity in mouse liver ischemia-reperfusion injury. Hepatology. 2012

6. McDonald B, Pittman K, Menezes GB, Hirota SA, Slaba I, Waterhouse CC, Beck PL, et al. Intravascular danger signals guide neutrophils to sites of sterile inflammation. Science. 2010; 330:362-366. [PubMed: 20947763]

7. Ji H, Shen XD, Zhang Y, Gao F, Huang CY, Chang WW, Lee C, et al. Activation of cyclic adenosine monophosphate-dependent protein kinase a signaling prevents liver ischemia/reperfusion injury in mice. Liver Transpl. 2012; 18:659-670. [PubMed: 22290937]

8. Hart ML, Gorzolla IC, Schittenhelm J, Robson SC, Eltzschig HK. SP1-dependent induction of CD39 facilitates hepatic ischemic preconditioning. J Immunol. 2010; 184:4017-4024. [PubMed: 20207994]

9. Hart ML, Much C, Gorzolla IC, Schittenhelm J, Kloor D, Stahl GL, Eltzschig HK. Extracellular adenosine production by ecto- $5^{\prime}$-nucleotidase protects during murine hepatic ischemic preconditioning. Gastroenterology. 2008; 135:1739-1750. e1733. [PubMed: 18804111]

10. Lappas CM, Day YJ, Marshall MA, Engelhard VH, Linden J. Adenosine A2A receptor activation reduces hepatic ischemia reperfusion injury by inhibiting CD1d-dependent NKT cell activation. $\mathrm{J}$ Exp Med. 2006; 203:2639-2648. [PubMed: 17088433]

11. Chouker A, Ohta A, Martignoni A, Lukashev D, Zacharia LC, Jackson EK, Schnermann J, et al. In vivo hypoxic preconditioning protects from warm liver ischemia-reperfusion injury through the adenosine A2B receptor. Transplantation. 2012; 94:894-902. [PubMed: 23073466]

12. Eltzschig HK, Abdulla P, Hoffman E, Hamilton KE, Daniels D, Schonfeld C, Loffler M, et al. HIF-1-dependent repression of equilibrative nucleoside transporter (ENT) in hypoxia. J Exp Med. 2005; 202:1493-1505. [PubMed: 16330813]

13. Grenz A, Bauerle JD, Dalton JH, Ridyard D, Badulak A, Tak E, McNamee EN, et al. Equilibrative nucleoside transporter ENT1 regulates post-ischemic blood-flow during acute kidney injury in mice. J Clin Invest. 2012 in press.

14. Loffler M, Morote-Garcia JC, Eltzschig SA, Coe IR, Eltzschig HK. Physiological roles of vascular nucleoside transporters. Arterioscler Thromb Vasc Biol. 2007; 27:1004-1013. [PubMed: 17332491]

15. Morote-Garcia JC, Rosenberger P, Nivillac NM, Coe IR, Eltzschig HK. Hypoxia-inducible factordependent repression of equilibrative nucleoside transporter 2 attenuates mucosal inflammation during intestinal hypoxia. Gastroenterology. 2009; 136:607-618. [PubMed: 19105964]

16. Sitkovsky MV, Lukashev D, Apasov S, Kojima H, Koshiba M, Caldwell C, Ohta A, et al. Physiological control of immune response and inflammatory tissue damage by hypoxia-inducible factors and adenosine A2A receptors. Annual Review of Immunology. 2004; 22:657-682.

17. Eltzschig HK, Sitkovsky MV, Robson SC. Purinergic signaling during inflammation. N Engl J Med. 2012; 367:2322-2333. [PubMed: 23234515]

18. Hart ML, Much C, Kohler D, Schittenhelm J, Gorzolla IC, Stahl GL, Eltzschig HK. Use of a hanging-weight system for liver ischemic preconditioning in mice. Am J Physiol Gastrointest Liver Physiol. 2008; 294:G1431-1440. [PubMed: 18436620]

19. Choi DS, Cascini MG, Mailliard W, Young H, Paredes P, McMahon T, Diamond I, et al. The type 1 equilibrative nucleoside transporter regulates ethanol intoxication and preference. Nat Neurosci. 2004

20. Grenz A, Bauerle JD, Dalton JH, Ridyard D, Badulak A, Tak E, McNamee EN, et al. Equilibrative nucleoside transporter 1 (ENT1) regulates postischemic blood flow during acute kidney injury in mice. J Clin Invest. 2012; 122:693-710. [PubMed: 22269324]

21. Liu W, Hou Y, Chen H, Wei H, Lin W, Li J, Zhang M, et al. Sample preparation method for isolation of single-cell types from mouse liver for proteomic studies. Proteomics. 2011; 11:35563564. [PubMed: 21751380]

22. Blackburn MR, Volmer JB, Thrasher JL, Zhong H, Crosby JR, Lee JJ, Kellems RE. Metabolic consequences of adenosine deaminase deficiency in mice are associated with defects in alveogenesis, pulmonary inflammation, and airway obstruction. J Exp Med. 2000; 192:159-170. [PubMed: 10899903] 
23. Lasley RD, Kristo G, Keith BJ, Mentzer RM Jr. The A2a/A2b receptor antagonist ZM-241385 blocks the cardioprotective effect of adenosine agonist pretreatment in in vivo rat myocardium. Am J Physiol Heart Circ Physiol. 2007; 292:H426-431. [PubMed: 16980350]

24. Eckle T, Krahn T, Grenz A, Kohler D, Mittelbronn M, Ledent C, Jacobson MA, et al. Cardioprotection by ecto-5'-nucleotidase (CD73) and A2B adenosine receptors. Circulation. 2007; 115:1581-1590. [PubMed: 17353435]

25. Grenz A, Osswald H, Eckle T, Yang D, Zhang H, Tran ZV, Klingel K, et al. The reno-vascular A2B adenosine receptor protects the kidney from ischemia. PLoS Med. 2008; 5:e137. [PubMed: 18578565]

26. Eltzschig HK, Abdulla P, Hoffman E, Hamilton KE, Daniels D, Schonfeld C, Loffler M, et al. HIF-1-dependent repression of equilibrative nucleoside transporter (ENT) in hypoxia. J Exp Med. 2005; 202:1493-1505. [PubMed: 16330813]

27. Eckle T, Grenz A, Kohler D, Redel A, Falk M, Rolauffs B, Osswald H, et al. Systematic evaluation of a novel model for cardiac ischemic preconditioning in mice. Am J Physiol Heart Circ Physiol. 2006; 291:H2533-2540. [PubMed: 16766632]

28. Eckle T, Fullbier L, Wehrmann M, Khoury J, Mittelbronn M, Ibla J, Rosenberger P, et al. Identification of ectonucleotidases CD39 and CD73 in innate protection during acute lung injury. J Immunol. 2007; 178:8127-8137. [PubMed: 17548651]

29. Eltzschig HK, Ibla JC, Furuta GT, Leonard MO, Jacobson KA, Enjyoji K, Robson SC, et al. Coordinated adenine nucleotide phosphohydrolysis and nucleoside signaling in posthypoxic endothelium: role of ectonucleotidases and adenosine A2B receptors. J Exp Med. 2003; 198:783796. [PubMed: 12939345]

30. Eltzschig HK, Thompson LF, Karhausen J, Cotta RJ, Ibla JC, Robson SC, Colgan SP. Endogenous adenosine produced during hypoxia attenuates neutrophil accumulation: coordination by extracellular nucleotide metabolism. Blood. 2004; 104:3986-3992. [PubMed: 15319286]

31. Synnestvedt K, Furuta GT, Comerford KM, Louis N, Karhausen J, Eltzschig HK, Hansen KR, et al. Ecto-5'-nucleotidase (CD73) regulation by hypoxia-inducible factor-1 mediates permeability changes in intestinal epithelia. J Clin Invest. 2002; 110:993-1002. [PubMed: 12370277]

32. Thompson LF, Eltzschig HK, Ibla JC, Van De Wiele CJ, Resta R, Morote-Garcia JC, Colgan SP. Crucial role for ecto-5'-nucleotidase (CD73) in vascular leakage during hypoxia. J Exp Med. 2004; 200:1395-1405. [PubMed: 15583013]

33. Eckle T, Faigle M, Grenz A, Laucher S, Thompson LF, Eltzschig HK. A2B adenosine receptor dampens hypoxia-induced vascular leak. Blood. 2008; 111:2024-2035. [PubMed: 18056839]

34. Eckle T, Grenz A, Laucher S, Eltzschig HK. A2B adenosine receptor signaling attenuates acute lung injury by enhancing alveolar fluid clearance in mice. J Clin Invest. 2008; 118:3301-3315. [PubMed: 18787641]

35. Eckle T, Kohler D, Lehmann R, El Kasmi KC, Eltzschig HK. Hypoxia-Inducible Factor-1 Is Central to Cardioprotection: A New Paradigm for Ischemic Preconditioning. Circulation. 2008; 118:166-175. [PubMed: 18591435]

36. Grenz A, Osswald H, Eckle T, Yang D, Zhang H, Tran ZV, Klingel K, et al. The Reno-Vascular A2B Adenosine Receptor Protects the Kidney from Ischemia. PLoS Medicine. 2008; 5:e137. [PubMed: 18578565]

37. Hart ML, Jacobi B, Schittenhelm J, Henn M, Eltzschig HK. Cutting Edge: A2B Adenosine receptor signaling provides potent protection during intestinal ischemia/reperfusion injury. $\mathrm{J}$ Immunol. 2009; 182:3965-3968. [PubMed: 19299692]

38. Ohta A, Sitkovsky M. Role of G-protein-coupled adenosine receptors in downregulation of inflammation and protection from tissue damage. Nature. 2001; 414:916-920. [PubMed: 11780065]

39. Sitkovsky M, Lukashev D. Regulation of immune cells by local-tissue oxygen tension: HIF1 alpha and adenosine receptors. Nat Rev Immunol. 2005; 5:712-721. [PubMed: 16110315]

40. Yang D, Zhang Y, Nguyen HG, Koupenova M, Chauhan AK, Makitalo M, Jones MR, et al. The A2B adenosine receptor protects against inflammation and excessive vascular adhesion. J Clin Invest. 2006; 116:1913-1923. [PubMed: 16823489] 
41. Cronstein BN, Daguma L, Nichols D, Hutchison AJ, Williams M. The adenosine/neutrophil paradox resolved: human neutrophils possess both A1 and A2 receptors that promote chemotaxis and inhibit O2 generation, respectively. J Clin Invest. 1990; 85:1150-1157. [PubMed: 2156895]

42. Aherne CM, Kewley EM, Eltzschig HK. The resurgence of A2B adenosine receptor signaling. Biochim Biophys Acta. 2011; 1808:1329-1339. [PubMed: 20546702]

43. Eltzschig HK, Rivera-Nieves J, Colgan SP. Targeting the A2B adenosine receptor during gastrointestinal ischemia and inflammation. Expert Opin Ther Targets. 2009; 13:1267-1277. [PubMed: 19769545]

44. Hart ML, Grenz A, Gorzolla IC, Schittenhelm J, Dalton JH, Eltzschig HK. Hypoxia-inducible factor-1alpha-dependent protection from intestinal ischemia/reperfusion injury involves ecto- $5^{\prime}$ nucleotidase (CD73) and the A2B adenosine receptor. J Immunol. 2011; 186:4367-4374. [PubMed: 21357264]

45. Koeppen M, Eckle T, Eltzschig HK. Interplay of hypoxia and A2B adenosine receptors in tissue protection. Adv Pharmacol. 2011; 61:145-186. [PubMed: 21586359]

46. Blackburn MR, Vance CO, Morschl E, Wilson CN. Adenosine receptors and inflammation. Handb Exp Pharmacol. 2009:215-269. [PubMed: 19639284]

47. Zhou Y, Schneider DJ, Morschl E, Song L, Pedroza M, Karmouty-Quintana H, Le T, et al. Distinct roles for the $\mathrm{A}(2 \mathrm{~B})$ adenosine receptor in acute and chronic stages of bleomycin-induced lung injury. J Immunol. 2011; 186:1097-1106. [PubMed: 21149612]

48. Zhang Y, Dai Y, Wen J, Zhang W, Grenz A, Sun H, Tao L, et al. Detrimental effects of adenosine signaling in sickle cell disease. Nat Med. 2011; 17:79-86. [PubMed: 21170046]

49. Eltzschig HK, Faigle M, Knapp S, Karhausen J, Ibla J, Rosenberger P, Odegard KC, et al. Endothelial catabolism of extracellular adenosine during hypoxia: the role of surface adenosine deaminase and CD26. Blood. 2006; 108:1602-1610. [PubMed: 16670267]

50. Peng Z, Borea PA, Wilder T, Yee H, Chiriboga L, Blackburn MR, Azzena G, et al. Adenosine signaling contributes to ethanol-induced fatty liver in mice. J Clin Invest. 2009; 119:582-594. [PubMed: 19221436]

51. Hasko G, Linden J, Cronstein B, Pacher P. Adenosine receptors: therapeutic aspects for inflammatory and immune diseases. Nat Rev Drug Discov. 2008; 7:759-770. [PubMed: 18758473] 

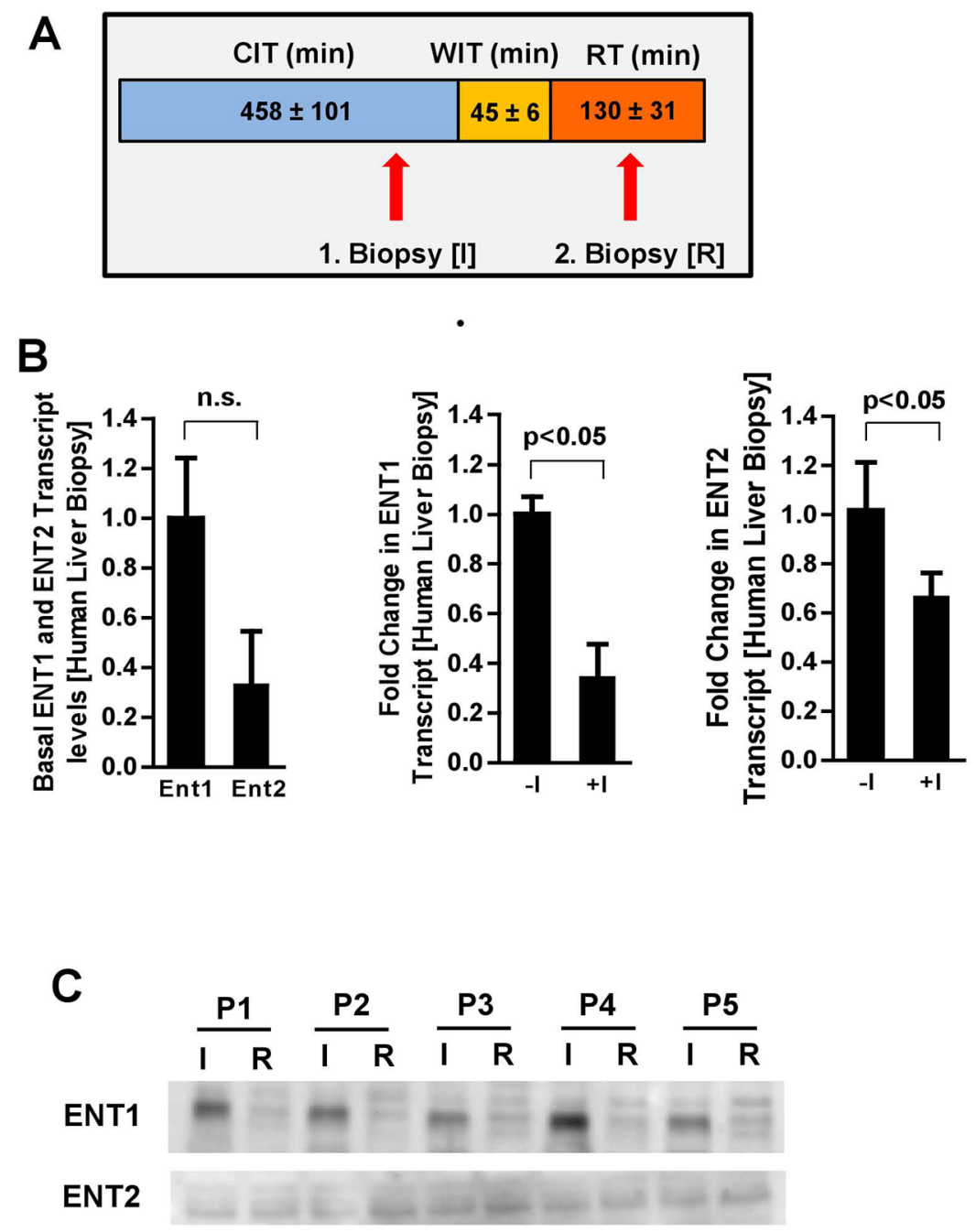

$\beta$-actin

Figure 1.

ENT1 and ENT2 expression in biopsies of human liver transplants following hepatic ischemia and reperfusion. (A) First liver biopsy was taken during ischemia (I) at the conclusion of cold ischemia time (CIT) during back table preparation of the cadaveric liver allograft. A second biopsy was taken during reperfusion $(\mathrm{R})$ after warm ischemia time (WIT) and reperfusion time (RT) immediately prior to closure of the abdomen following drain placement. (B) ENT1 and ENT2 transcript levels in biopsies of human liver transplants during cold ischemia (I) and after reperfusion (R); $(n=3-4$ independent experiments). (C) ENT1 and ENT2 protein levels (one representative blot of two is shown). 
A

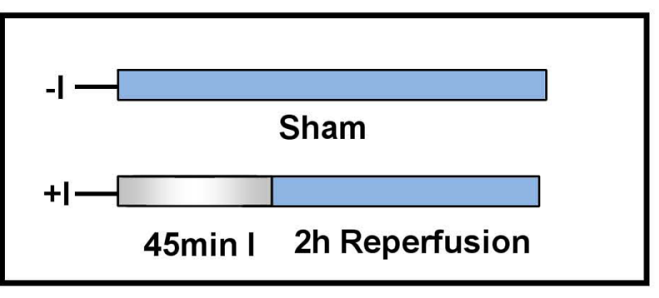

B
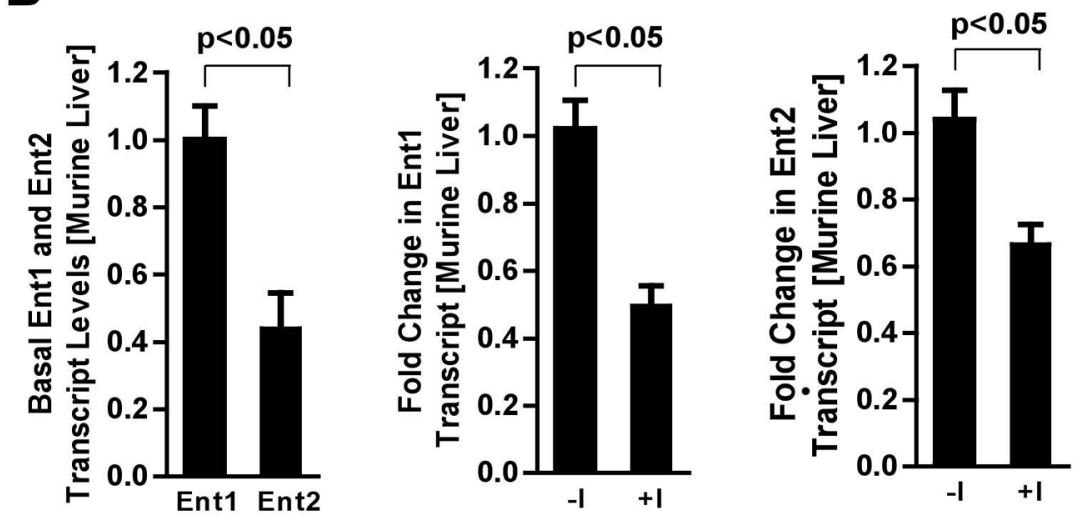

C

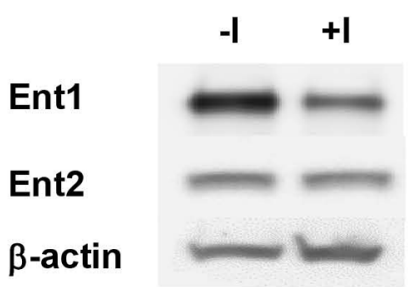

Figure 2.

ENT1 and ENT2 expression in murine livers following hepatic ischemia and reperfusion. (A) The left lobe of the liver was exposed to $45 \mathrm{~min}$ of ischemia followed by $2 \mathrm{~h}$ of reperfusion. (B) Ent1 and Ent2 transcript levels in left livers exposed to Sham operation (0) or $45 \mathrm{~min}$ of ischemia followed by $2 \mathrm{~h}$ reperfusion ( $\mathrm{n}=3-4$ independent experiments). (C) Ent1 and Ent2 protein levels ( $\beta$-actin to control for loading conditions; one representative blot of three is shown). 
A

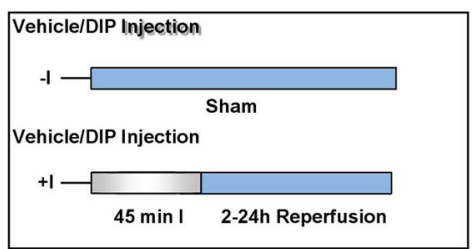

B

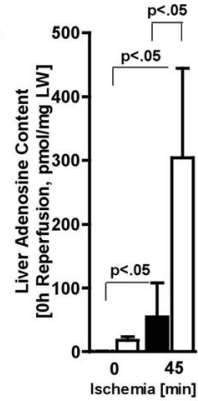

C
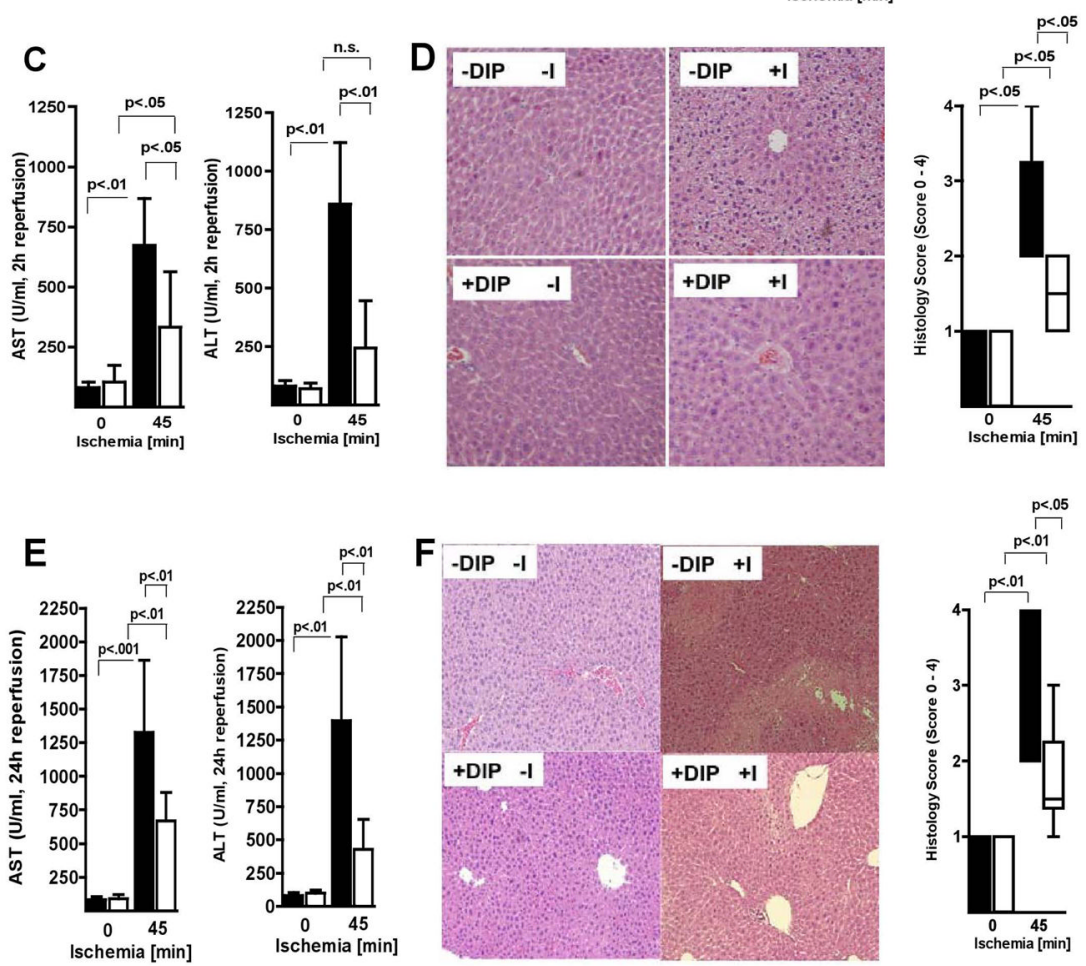

Figure 3.

Ischemic liver injury following inhibition of adenosine transporters during hepatic ischemia and reperfusion. (A) Experimental set-up to study liver ischemia and reperfusion with (black bar) and without (white bar) dipyridamole (DIP) treatment $(0.25 \mathrm{mg} / 25 \mathrm{~g}$ mouse IV). (B) Liver adenosine content measured immediately following $45 \mathrm{~min}$ of liver ischemia with or without DIP treatment. Wild-type mice with or without DIP treatment were exposed to (C,D) 45 min of liver ischemia and $2 \mathrm{~h}$ of reperfusion or (E,F) prolonged reperfusion (24h) before liver function was assessed by measurement of AST, ALT, liver histology (200-fold magnification; 1 of 3 representative slides is shown) and quantification of histologic tissue injury (Suzuki Scoring Index, 0-4); (n=4-6). 
$\square$ WT $\square$ Ent1\%
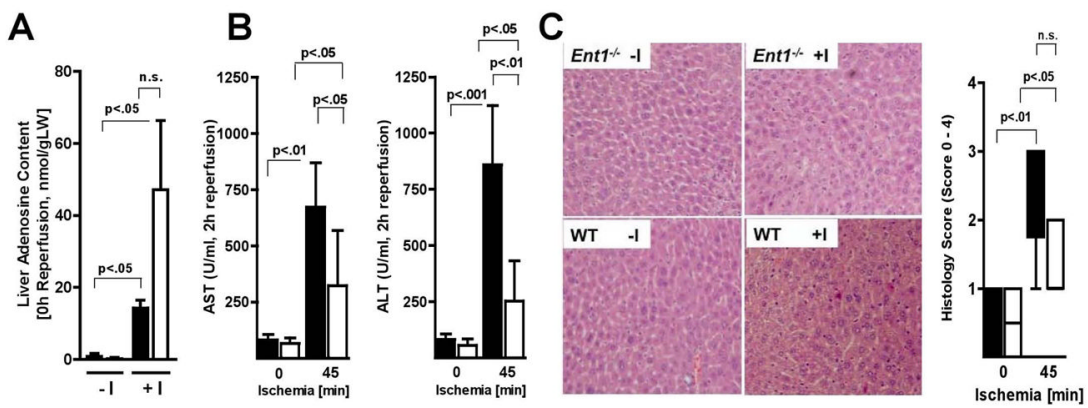

D
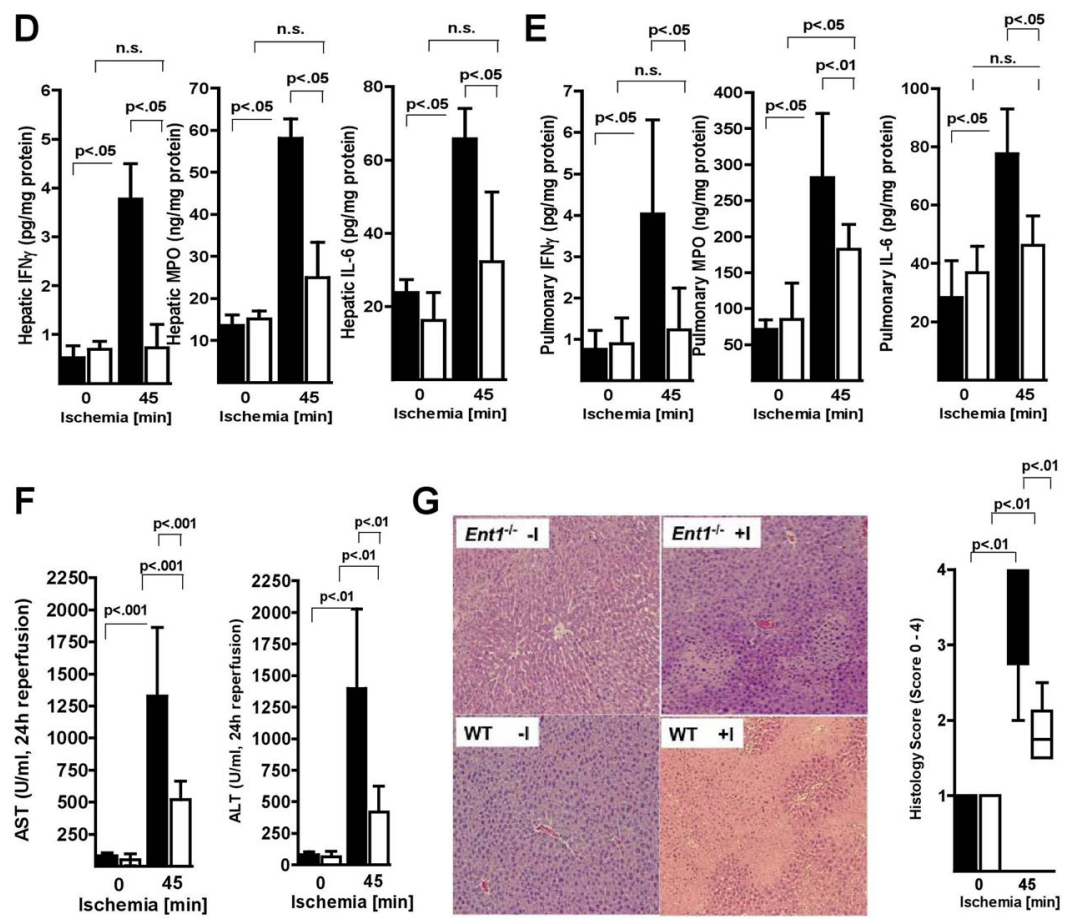

Figure 4.

Ischemic liver injury in mice gene-targeted for the equilibrative nucleoside transporter 1. (A) Liver adenosine content measured immediately following $45 \mathrm{~min}$ of liver ischemia in Ent1 ${ }^{-/-}$mice (white bar) or littermate controls (black bar). (B-E) Ent1 ${ }^{-/-}$mice or littermate controls were exposed to $45 \mathrm{~min}$ of liver ischemia and $2 \mathrm{~h}$ of reperfusion before liver function was assessed by measurement of (B) AST, ALT, (C) liver histology (200-fold magnification; 1 of 3 representative slides is shown) and quantification of histologic tissue injury (Suzuki Scoring Index, 0-4); $(\mathrm{n}=4-6)$; (D) liver inflammation was assessed by measurement of IFN $\gamma$, IL-6 protein levels and neutrophil marker myeloperoxidase (MPO) in livers and (E) lung inflammation was assessed by measuring IFN $\gamma$, IL-6 and MPO in lungs. $(\mathbf{F}, \mathbf{G})$ Ent $^{-/-}$mice or littermate controls were exposed to $45 \mathrm{~min}$ of liver ischemia and $24 \mathrm{~h}$ of reperfusion before liver function was assessed by measurement of AST, ALT, liver histology (200-fold magnification; 1 of 3 representative slides is shown) and quantification of histologic tissue injury (Suzuki Scoring Index, 0-4); ( $n=4-6)$. 

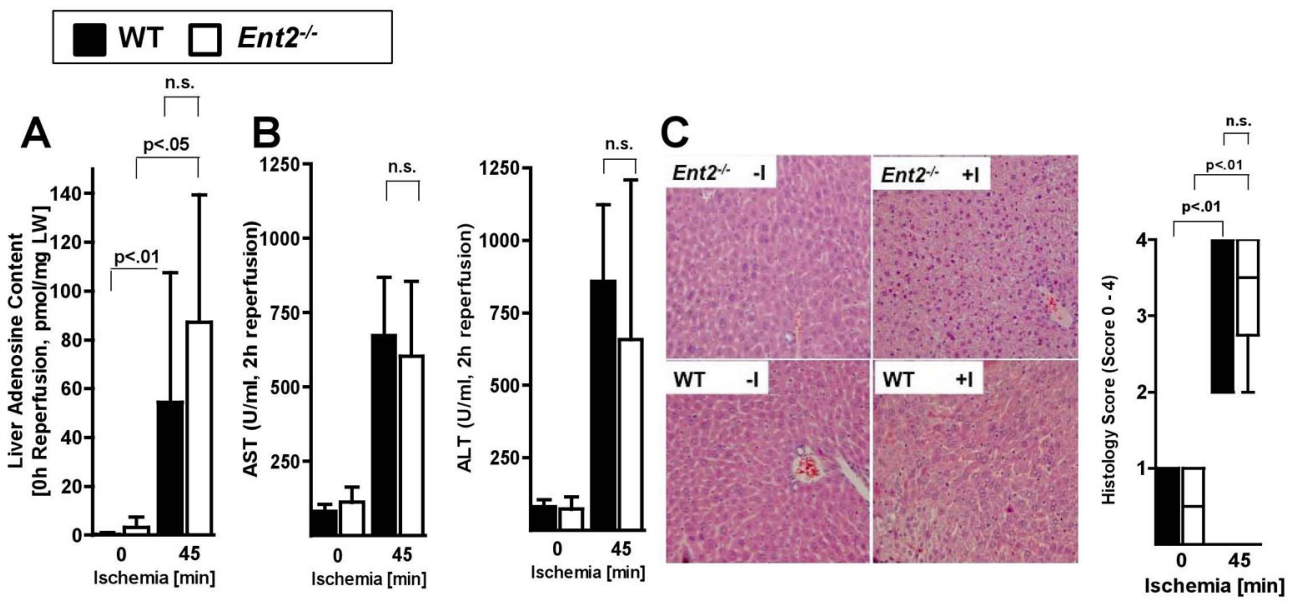

D
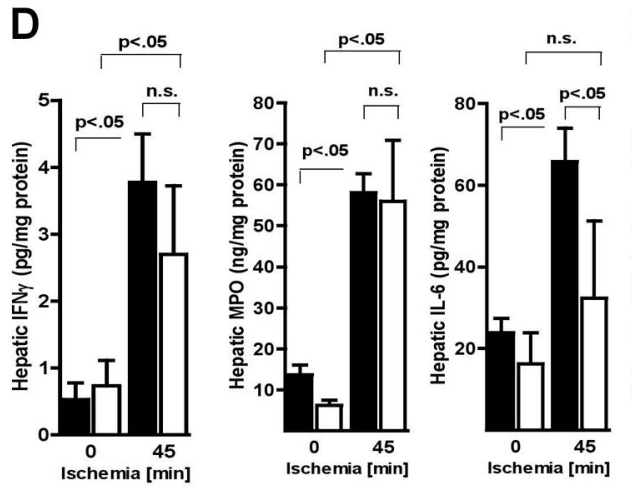

$\mathrm{E}$
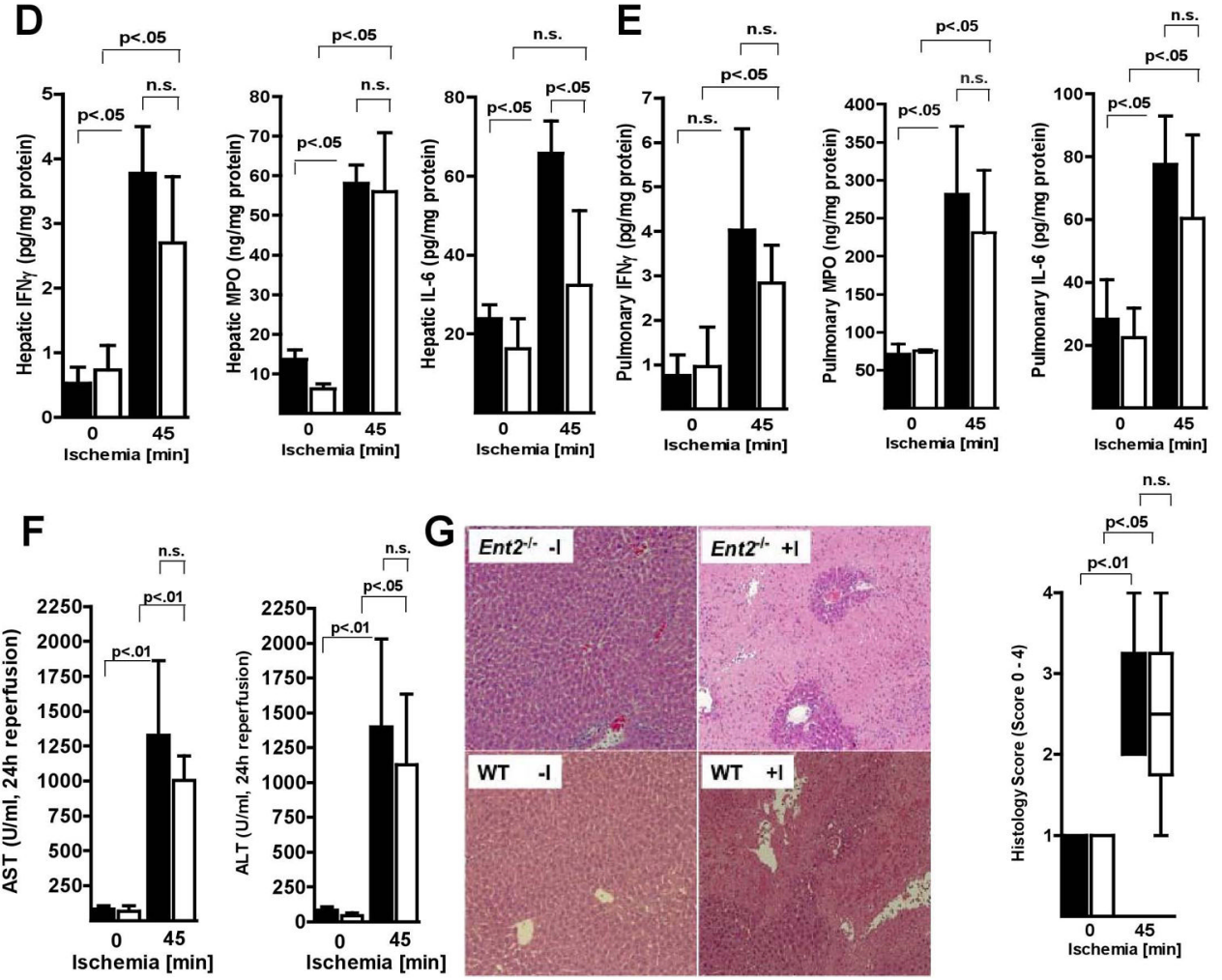

Figure 5.

Ischemic liver injury in mice gene-targeted for the equilibrative nucleoside transporter 2. (A) Liver adenosine content measured immediately following $45 \mathrm{~min}$ of liver ischemia in Ent $2^{-/-}$mice (white bar) or littermate controls (black bar). (B-E) Ent $2^{-/-}$mice or littermate controls were exposed to $45 \mathrm{~min}$ of liver ischemia and $2 \mathrm{~h}$ of reperfusion before liver function was assessed by measurement of (B) AST, ALT, (C) liver histology (200-fold magnification; 1 of 3 representative slides is shown) and quantification of histologic tissue injury (Suzuki Scoring Index, 0-4); $(\mathrm{n}=4-6)$; (D) liver inflammation was assessed by measurement of IFN $\gamma$, IL-6 protein levels and neutrophil marker myeloperoxidase (MPO) in livers and (E) lung inflammation was assessed by measuring IFN $\gamma$, IL-6 and MPO in lungs. $(\mathbf{F}, \mathbf{G}) E n t 2^{-/-}$mice or littermate controls were exposed to $45 \mathrm{~min}$ of liver ischemia and $24 \mathrm{~h}$ of reperfusion before liver function was assessed by measurement of AST, ALT, liver 
histology (200-fold magnification; 1 of 3 representative slides is shown) and quantification of histologic tissue injury (Suzuki Scoring Index, 0-4); ( $n=4-6)$. 
Ent1 ${ }^{1}-Z M 241385 \square E n t 1+Z M 241385$
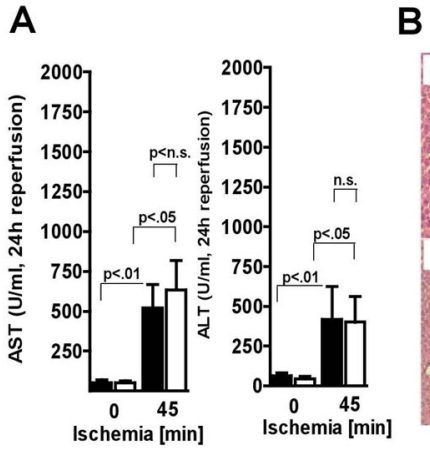

B

Ent1\%-PSB1115 $\square$ Ent1 +PSB1115

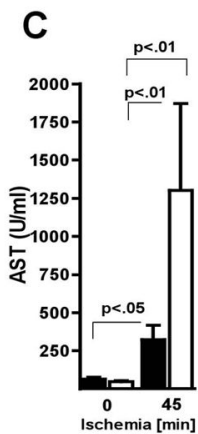

D
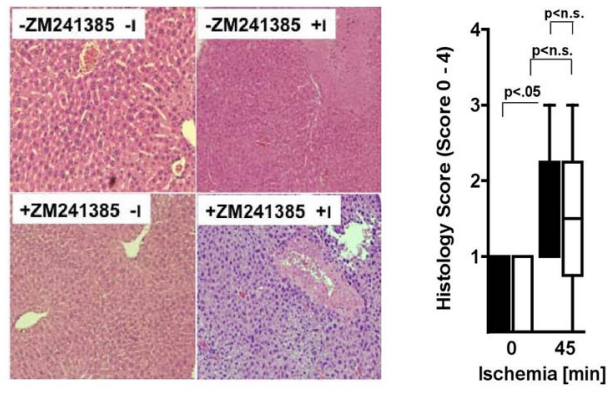

E
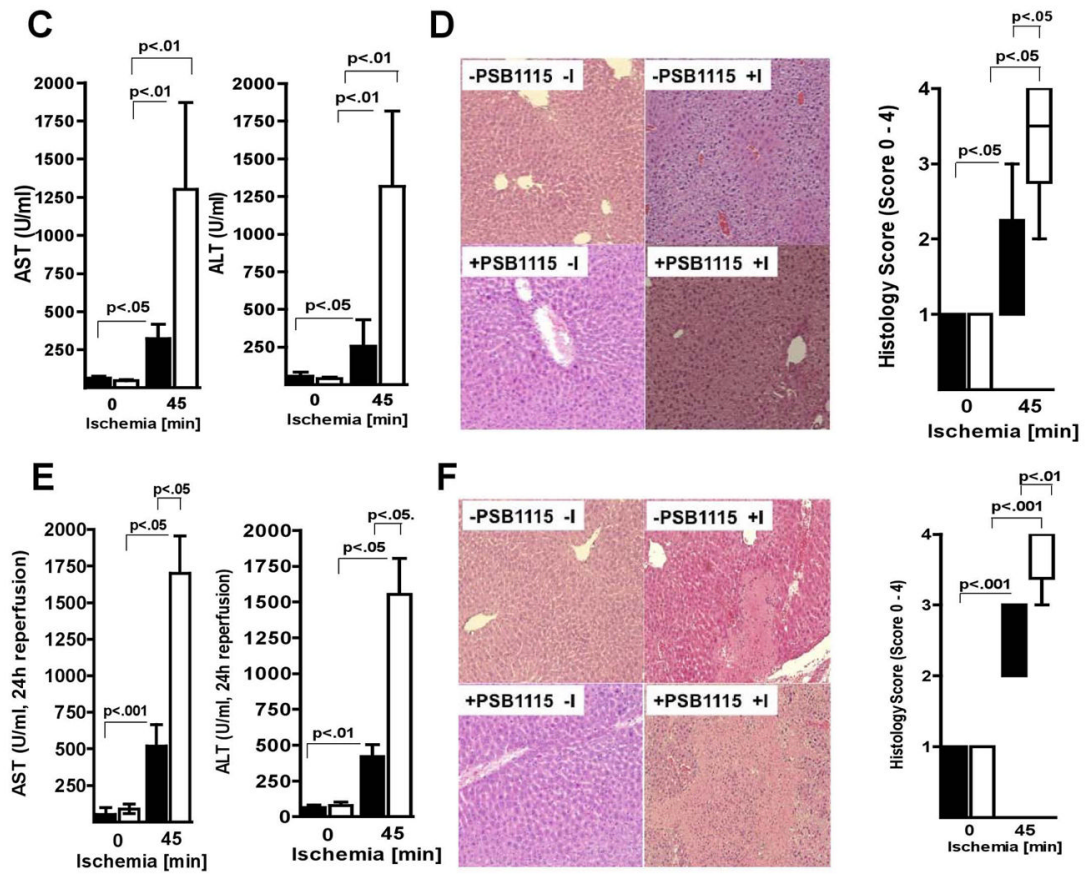

$F$
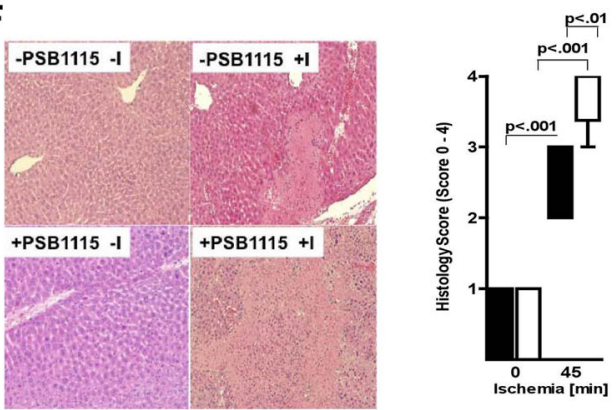

Figure 6.

Role of adenosine signaling in Ent1 $1^{-/-}$mice. $(\mathbf{A}, \mathbf{B}) E n t 1^{-/-}$mice were treated with an Adora2a specific antagonist ZM241385 (2mg/kg IV, white bar) or vehicle (black bar) and subsequently exposed to $45 \mathrm{~min}$ of liver ischemia and $24 \mathrm{~h}$ of reperfusion before liver function was assessed by measurement of AST, ALT, liver histology (200-fold magnification; 1 of 3 representative slides is shown) and quantification of histologic tissue injury (Suzuki Scoring Index, 0-4). Ent1 ${ }^{-/-}$mice were treated with an Adora2b specific antagonist PSB1115 (0.5 mg/25g mouse IV, white bar) or vehicle (black bar) and subsequently exposed to $(\mathbf{C}, \mathbf{D}) 45 \mathrm{~min}$ of liver ischemia and $2 \mathrm{~h}$ of reperfusion or $(\mathbf{E}, \mathbf{F})$ prolonged reperfusion (24h) before liver function was assessed by measurement of AST, ALT, liver histology (200-fold magnification; 1 of 3 representative slides is shown) and quantification of histologic tissue injury (Suzuki Scoring Index, 0-4). 


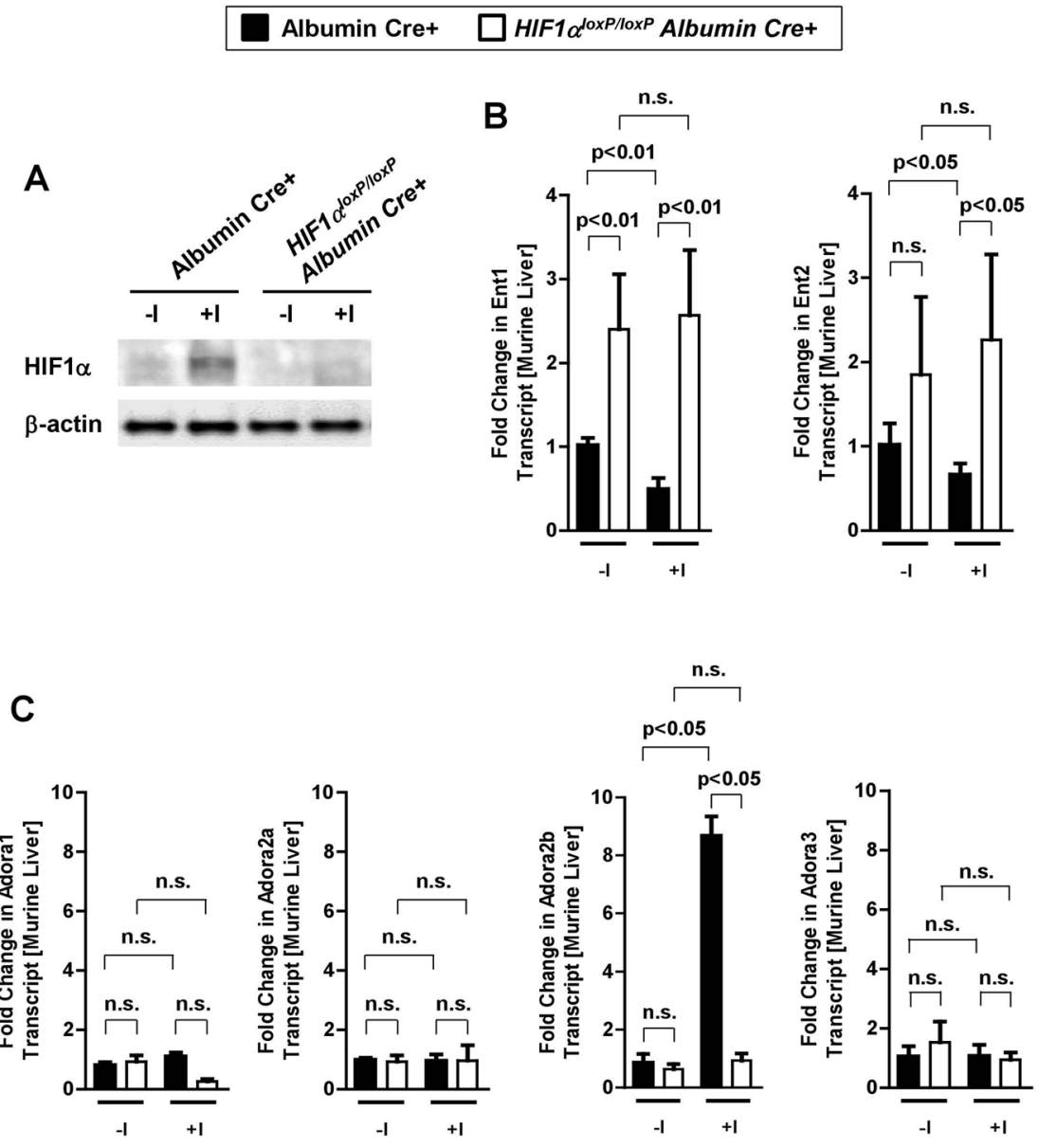

Figure 7. Role of HIF1 $\gamma$ in regulating hepatic ENT and Adora receptor expression

(A) HIF $1 \gamma$ expression in isolated hepatocytes of Adora $2 b^{\text {loxP/loxP }}$ Albumin Cre+ and Albumin Cre+ control mice with and without liver ischemia. (B) Ent1 and Ent2 transcript levels in left livers of Adora $2 b^{\text {loxP/loxP }}$ Albumin Cre+ and Albumin Cre+ control mice exposed to Sham operation (-I) or $45 \mathrm{~min}$ of ischemia $(+\mathrm{I})$ followed by $2 \mathrm{~h}$ reperfusion $(\mathrm{n}=3-$ 4 independent experiments). (C) Adora1, Adora2a, Adora2b and Adora3 transcript levels in left livers of Adora2b loxP/loxP Albumin Cre+ and Albumin Cre+ control mice exposed to Sham operation $(-\mathrm{I})$ or $45 \mathrm{~min}$ of ischemia $(+\mathrm{I})$ followed by $2 \mathrm{~h}$ reperfusion $(\mathrm{n}=3-4$ independent experiments). 


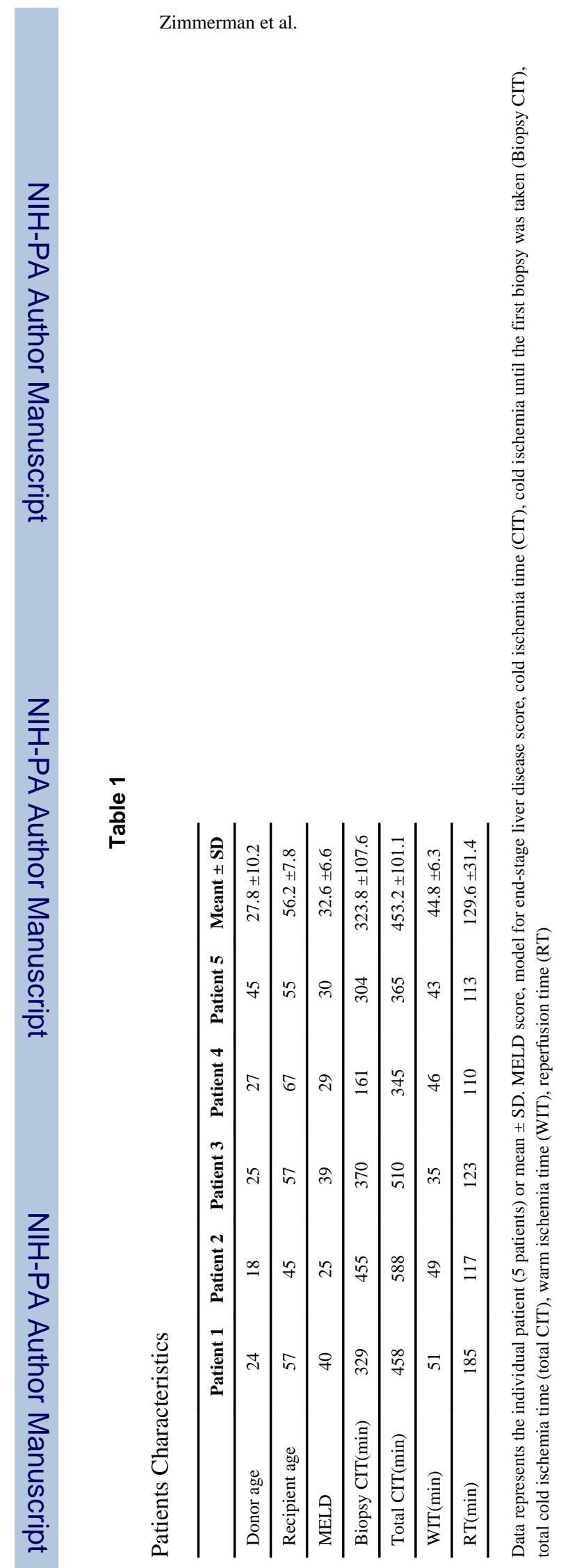

Hepatology. Author manuscript; available in PMC 2014 November 01. 